\title{
NEO-MYTHS: ISSUE-ATTENTION CYCLES AS MEDIATIZED SOCIAL DRAMAS
}

\author{
Arvydas Grišinas \\ Kaunas University of Technology
}

\begin{abstract}
This article suggests that in times of digital mass media, mediatized political issues create a self-perpetuating phenomenon that is here titled a neo-myth. Through combining interdisciplinary theories of Issue-Attention Cycles and Social Dramas, the article argues that the standardized ways that political issues are framed, mass-mediated and consumed in a contemporary society, paradoxically create a cyclical and self-perpetuating pattern. Instead of being linear, rational and cause-to-solution oriented, they become stereotypical, cyclical and performative, thus resembling mythological patterns both content and form-wise. The article discusses how and why these neo-myths form, as well as how political, public and media actors interact within the process. It discusses them in terms of their emergence, structure, causality, processual logics and formal variety, and suggests that the phenomenon falls in line with the findings of recent research on the shifting knowledge patterns in times of digital culture.
\end{abstract}

Keywords: neo-myth, news wave, social drama, issue-attention cycle, media, mediatization

DOI: https//doi.org/10.3176/tr.2022.1.04

Received 2 November 2021, accepted 7 January 2022, printed and available online 10 March 2022

\section{Introduction}

A popular narrative holds modern myths to be false beliefs, legends or ideas that people tend to uphold in modern societies despite them being wrong (meaning, counter-factual) or un-scientific (meaning, not proven empirically). In times that are 
on the contrary considered rational, information-driven and grounded in scientific factuality, these myths are held as a curious oddity at best and a dangerous piece of disinformation at worst. Recent developments of the public sphere, however, such as post-truth politics, and mediatization, render political dynamics ever more dependent on performative dramatization in the news and social media (Strömbäck and Esser 2014). With digital technology becoming ever more complex and obscure to the non-specialist users, some authors argue that we are re-entering a type of a 'new dark age', where mythological thinking is regaining traction (Bridle 2019).

Much of the mid-twentieth century research has demonstrated that myths are born from traditional, long-term practical and performative participation in social life, which is then rationalized and explained using standard representative narrative structures or archetypical symbolism (Jung 1928, Campbell 1993, Eliade 1971). Campbell (1972) also demonstrates how there are mythological constructions that are manifest in the contemporary societies, and that we actually need them to make sense of the world and our own lives.

It is, however, difficult for a culture that relies on linear, literary and factually grounded legal narratives to comfortably accommodate the deeper, archetypical meanings of this cyclical and archetypically grounded mode of communication and public conduct. This is why as Roland Barthes (1957) demonstrated, modern myths tend to be rather shallow and stereotypical. In other words, they retain the mythological structure of myths that are grounded in archetypes, but are more fluid, more consciously constructed and grounded in stereotypes and schemas. As evidenced by just about any marketing strategy in the world, there are patterns of public discourse and behavior that can be if not mapped and capitalized on, then at least recognized and triggered.

Through proposing a concept of a 'neo-myth', this article therefore intends to provoke a discussion on the idea that digital public sphere is essentially performative, schematic and cyclical. With this intent, it combines the concept of a 'social drama' (Turner 1980) and its stereotypical narrative structure with literature on mediated 'issue-attention cycles' (Downs 1976). It argues that many contemporary news issues can be understood as a type of publicly reproduced neo-myths. Social dramas have not only become central objects of mediated news content but are also themselves structuring the political process. This renders performativity and narrativity central to how political issues are being experienced and participated in. Some authors argue that this magnifies in times of digitalization as a result of a 'Gutenberg parenthesis' (Pettitt 2012), where linear, singular and strictly-ordered forms of literary knowledge give way to plural, performative and fluid forms of digital knowledge.

This article does not propose a finalized theory of contemporary mythology. However, it presents a sketch thereof, through studying the literature on masscommunication and issue attention cycles and asks, how are these neo-myths produced, facilitated, structured and how do they function in a contemporary society? It concludes the inquiry by exploring patterns of variation in these social dramas and performances, and possible reasons thereof. 


\section{The mediated birth of a neo-myth}

Information, data and news, as well as social networks, through which all of the latter is being shared, consumed and re-cycled, constitute the lifeblood of today's societies. It seems that endless streams of knowledge, advertising and gossip fill every moment of our paper coffee cup-holding, permanently-commuting, smartphone-scrolling, bitcoin-shopping life. However, while the amount of circulating knowledge grows exponentially, human capacity to process this information remains limited. This is no secret neither to the academic community, nor to the world of news and technology, which is why social media employs algorithms to filter our information intake, and news media use catchy headlines to capture viewers' attention (Teixeira 2015).

According to Downs (1976), the public attention cycle is triggered by a certain revelation or sensationalization of an issue within the society. Nowadays, in most cases, this revelation would certainly derive from the proliferation of the news in either the social or traditional media and would heavily rely on how it is framed and represented. According to Schaffner and Sellers (2009), framing is depicting an issue in one way and not the other, excluding potential other interpretations. There is a rich body of literature discussing a variety of frames, both general, case-specific and hybrid (Boydstun et al. 2013). However, it all agrees that news media uses frames to shape the vision of social and political issues in a particular way.

Semetko and Valkenburg (2000) describe five main framing categories that can potentially be applied to most issues. In a way they can be considered stereotypes that are being used in structuring or schematizing social drama. These are the responsibility frame, the conflict frame, the economic consequences frame, the human-interest frame and the morality frame. Their approach is based on Neuman et al. (1992) who identified the most frequent frames used in the US media. They also demonstrated that these categories are widely used in the European media as well. Nisbet and Kroepsch (2003) note that some of the frames are more dramatic than others. Hence, they are more likely to be found during the stage of rising public interest in the issue than during the period of waning public interest. Media frames become vehicles for representing reality as well as knowledge thereof in a meaningful and symbolic yet somewhat simplistic, stereotypical and distorted, or, so to say, neo-mythological way. Thus, specific standardized representations of reality organize the complex issues into meaningful and reproducible units of communication (Reese 2001: 10-12).

Liu, Vedlitz and Alston (2008) demonstrate how peaks of issue salience are also connected to different world events that have associative meaning to issues at hand and trigger certain hypes of media interest. Therefore, there is a strong relation between how news is framed and depicted in the media, and the public experience of the social drama. Post-truth and populist politics, but most recently the COVID-19 pandemic demonstrated how simplistic yet emotionally charged narratives have a way to capture people's interest and attention, as well as affect policymaking. For instance, research done by Brookings Institution shows that in the US, "Republicans consistently underestimate risks, while Democrats consistently overestimate them" (Rothwell and Desai 2021). 
It is therefore the mediated performative and standardized dramatization of social and political issues that creates neo-myths. A neo-myth is hence a schematic news story that is mediated, received and performed in public, in accordance to media frame-defined scripts. It might be too far-fetched to call these scripts archetypical in a Jungian sense. Yet it would not be too far-fetched to call them stereotypical. Here are some of the most popular contemporary stereotypical scripts for public neomyths: a school shooting in the U.S., a refugee crisis in Greece, a breach of human rights in Russia, and so on. These are real-world political issues, yet they have a stereotypically recognizable form and a predictable narrative content.

They in their turn also produce predictable reactions from public and politicians. It is as if under cue that the public becomes outraged by some events and utterances, and worried, sending their 'thoughts and prayers' during other events. At certain stages of the script, politicians feel compelled, or a proper tone requires them to express their opinion, while specialists are urged to explain the contents of the issue at hand (Thunström and Noy 2019). There is thus a certain choreography to how a social drama is being performed and mediated in the public sphere. The characters and circumstances in these social dramas change, but the plot and the performance remain schematic and stereotypical.

The processes of mythologization of public sphere are further accelerated since especially during the COVID-19 pandemic, a large portion of our life, both private and public, moved online, and our media consumption has risen drastically (COVID-19: tracking the impact on media consumption 2020). What this means is that political processes ever more depend on the market dynamics of mass media. Social and political dramas and the way they are being framed and represented in the media, in that sense become schematic in accordance to the news cycles of the media. In other words, social and policy issues are being dramatized, mediated and played out according to a specific logic, which is media-friendly and can fit popular narratives.

The idea of mediatization became popularized in social sciences, and specifically in communication and media studies over the last decade. It denotes the process during which politicians and public agents alter their behavior and political practices to better suit the 'media logic' rather than 'political logics' (Strömbäck and Esser 2014). Donald Trump's Twitter politics is the first example that comes to mind thinking about the topic, however, it is easy to think of many other cases when politicians either behave and formulate their thoughts in ways that could be easily mediated and published (taking selfies not excluded) or use the powers of mass media as a political vehicle (Stier et al. 2018).

This, however, not only happens in terms of the way issues are being depicted by the media, but it is precisely due to the processes of mediatization that they are also performatively executed and experienced in a dramatic way (Kalpokas 2019). Consequentially, competition for public attention not only fuels the processes of policymaking, but also structures the very nature of how issues are presented, framed and delivered. It is a 'story', the collectively experienced drama that constitutes the mediatized neo-myth. With the digitalization and mediatization of political and 
public performances, these mass-consumed stereotypical media scripts gain ever more influence.

\section{The structure of a neo-myth}

Neo-myth is not just a story. In its intent, it is also a performance, insofar as, according to Eliade (1971), it is an archetypical model of both knowledge and conduct. A neo-myth entails both the narrative that is being told and reciprocated within the society, and the society's own behavior in accordance with the myth's stereotypical script. Communication research uses framing and narrative analysis to explore the content of social dramas and issue mediation (Boydstun et al. 2013, Nisbet et al. 2007, Semetko and Valkenburg 2000, etc.). Meanwhile, in a broader cultural sense, the social dramas are studied by symbolic and interpretative anthropology (Turner 1980). At the same token, the formal, behavioral aspect of these social dramas has been conceptualized as issue-attention cycles (Downs 1972) and adopted in communication studies (Lörcher and Neverla 2015, Waldherr 2012, Geiß 2018, etc.). It is through understanding both the content and form of these processes that we can better grasp the nature and structure of the contemporary neo-myths.

The concept of social drama has been popularized by an anthropologist Victor Turner in his discussion of liminal and liminoid situations when a society is experiencing some kind of transition or crisis (Turner 1974). It may happen due to a conflict, a need for change, a sudden disrupting event or other reason, but it affects the society in a meaningful way. Moreover, as Turner argues, it is a universal phenomenon, and while it has local and cultural contingencies, it nevertheless is structured in a common, four-staged manner (149).

The term has since been adapted by the culturalist brand of sociology and used to explain the deeper meanings behind a variety of political and social processes (Alexander 2017). Turner himself used this term to imply that all societies experience social life as a series of dramatic events which have several distinct stages: breach, crisis, redressive action and reintegration or recognition of schism (Turner 1980: 149). According to him, there is therefore a certain pattern in which societies experience social dramas and make sense of them.

In parallel, studying a similar phenomenon of large-scale public behavior in relation to an overarching social issue, Anthony Downs (1972) formulated his theory of issue-attention cycles in which he discussed the way that the American public reacted to environmental issues in the press. Similarly, to the dramatic content that Turner discussed, according to Downs, issue-attention life cycles progress from obscurity and limited debate towards increasing public awareness and, eventually towards becoming institutionalized policy decisions, as they gradually fade away from the focus of the media, only to potentially be re-ignited by some triggering event in the future.

Downs describes an attention cycle as consisting of five stages: the pre-problem stage, when the broader public is unaware of the problem; the alarmed discovery 
and euphoric enthusiasm, realizing the cost of significant progress, gradual decline of intense public interest; and the post-problem stage, when attention to the issue declines, but the change in terms of policies and implementations remains, rendering the possibility of another issue-attention cycle to initiate in the future (Gupta and Jenkins-Smith 2016). Together with the dynamics of the content of the social drama, the issue-attention cycle can be represented in a scheme, outlining a schematic representation of the neo-myth.

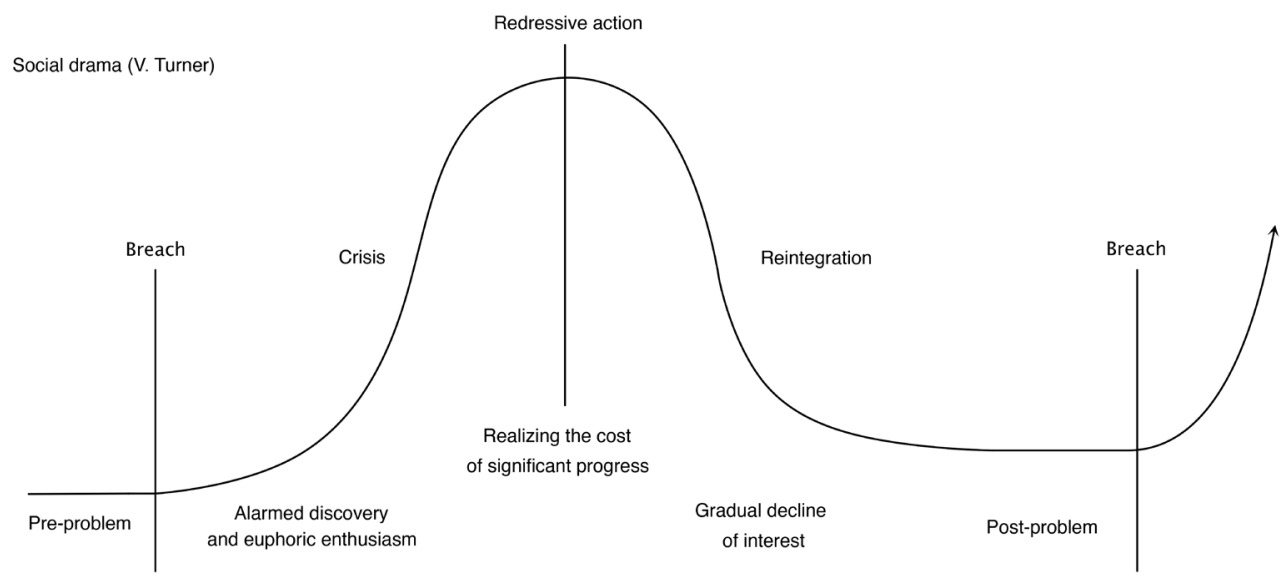

Issue-attention life cycles (A. Downs)

Figure 1. The scheme of a news wave and Downs's periodization of an issue-attention cycle, which are popularly used in communication studies, depicts the quantity fluctuation in public attention. However, Turner's periodization adds the analytic layer of the dramatic content. It can be seen from the model that the dramatic content and the public behavior correspond to a similar scheme, which constitutes the framework of the neo-myth.

One standard scenario of a neo-myth, for example, could be this: a nonWestern country behaves in a way that is unacceptable according to the Western norms (Breach). The public expresses concern on mass and social media (Alarmed discovery), the pro-Western part of the public patronizes and demands justice while the anti-Western part advocates and points to Western world's own ills and fallacies (Crisis). Perhaps someone is 'cancelled' or ritualistically segregated due to utterances or behaviors that are considered symbolically 'dirty' (Redressive action). Perhaps it is realized that the economic price of declaring sanctions on the perpetrator are too high (Realizing costs). Eventually a resolution is found (Reintegration), or other social dramas distract public attention towards other neo-myths (Gradual decline of interest), and the cycle continues (Post-problem). This schematic illustration is recognizable and similar to many international and local social dramas, and the actors can vary. Yet there is usually a recurring schematicism to the process, which both Turner and Downs notice. 
Stayner (2014) discusses a similar phenomenon of a media hype, which also has several stages, broadly coinciding with Downs's model. He suggests that it begins with a trigger event that is widely recognized as significant in the society. The length and duration of a media hype depends on several factors, including whether the same issue is framed in a similar way by several media outlets, whether other events take place, which can be connected to the issue, whether the issue is considered controversial, and whether the elites are actively participating in the discussion. Waldherr (2014), in her turn, also points out that an issue attention rises and the cycles are more dense if the reporting is heterogeneous. This suggests that the more dramatic the neo-myth is content-wise, and the broader and more complex the participation of the media and society form-wise, the more impact the neo-myth has on both the public, and the discursive level. Narrative controversy and social complexity thus allow for neo-myths to exert more influence on the society, thus impacting both media reporting and political action.

\section{The chicken or the egg? A cyclical solution to a linear problem}

At this juncture, a question of causality begs to be resolved. Is media a passive reflector (conduit) of issues and social dramas, or an active participant (contributor) in the news life cycles that perpetuate them? Literature seems to somewhat disagree on the topic. Bacot and Fitzgerald (2008) argue that media plays a tremendous role in shaping what the public considers important, one of the reasons being that it is capable of presenting complex issues in a simplistic manner. For instance, Arendt and Scherr (2019) demonstrate that the rise in news reporting on measles outbreak in Austria was immediately followed by a rise in vaccinations.

Shanahan, McBeth and Hathaway (2008) suggest news reporting structures issueattention cycles not only via practices of framing, but also through creating media hypes, which, regardless of the veracity of the message, create resonance within the public, especially in conjunction with the spread of news in the social media. According to Djerf-Pierre (2011), "Most studies on issue cycles in the media ... apply a wider definition, adhering to the (constructivist) sociological definition of issues as matters of public concern that involve contending views/interests (Molotch and Lester 1974, Hilgartner and Bosk 1988), as opposed to the political science notion of issues as public matters involving political institutions." Therefore, the disagreement seems to be of an academic disciplinary rather than empirical nature.

It is true, however, that policymakers also have an important role in shaping both the process of the social drama and the representation thereof in the media. In the political sciences literature, framing is often considered a second-level agenda setting (McCombs 2004, Crow and Lawlor 2016). Policymakers not only react to media hypes, but also influence the agenda-setting practices. In his discussion on issue-attention cycles, Downs (1972) discusses the input from public policy, arguing that public attention incentivizes policymakers to address the issue, but at the same time, as it is being addressed, the public realizes the complexity of an issue and loses interest, cycling the issue back into a dormant stage. 
As revealed by Hilgartner and Bosk (1988), policymakers have an important role in selecting the articulations of an issue, which affects the trajectory of future attention-cycles. Gupta and Jenkins-Smith (2016) quote studies that show how public policy activity usually initiates after public attention has peaked. However, this position has been debated by Howlett (1992) studying the Canadian case and attributing the variation to differences in structure of governance compared to the US.

Nisbet, et al. (2007: 225) also notice that dramatic, emotionally charged frames as well as increased discursive activity of politicians, participants and opinion-makers in the media correlate with the period of rising public interest towards the issue at hand. Meanwhile, the more technical frames and activity of specialists, technical experts and others engaging in more of an administrative discourse, are used during the recess of public interest. In their case, because the US administration was capable of maintaining a technical framing of the topic, public interest in plant biotechnology remained mild.

However, if we consider that neo-myths are cyclical, and that the society experiences social dramas in several waves of attention, a middle ground with regards to causality can be found. According to de Vreese (2015), frames can be both a dependent variable, if studied as a result of decisions made in the newsroom and broader society, and as an independent variable if studied as a precursor to societal change. As such, different frames become 'alternative ways of defining issues, endogenous to the political and social world' (53). This, as Nisbet et al. (2007) argue, is represented in the types of frames and agents that form the discourse, as well as the tone of the articles at different stages of the cycle.

Studying news waves in Israel, Wolfsfeld and Sheafer (2006) find that the major factor in triggering newswaves is political elites (54\%), followed by accidents or blunders (28\%). However, they also emphasize that all political actors are in return dependent on media attention that to different degrees is generated by news waves. The problem of causality can therefore be resolved when it is perceived as a cyclical and self-perpetuating process. The neo-myth needs a breach event to start or reignite the performance. For instance, Wolfsfeld and Sheafer (2006) emphasize the role of political actors in starting a news wave. Yet at a later stage, the social drama itself pushes politicians to react, participate and perform in accordance with the neomyths mediated logic.

\section{What makes them tick? The rise and wane of a neo-myth}

Now that it has been established that contemporary neo-myths are cyclical, performative and stereotypical, it is worthwhile discussing how they are initiated, why they become prevalent, and how they dissolve. Many authors agree that social dramas are initiated by a breach event that creates a news hype or a rise in public attention. Vesterman (2005) argues that media, by inflating the reporting on a specific topic, encourages the process of social amplification, which then translates into 
social, economic and policy contexts. He suggests that due to the constant looping coverage of a trigger event and related news, a 'news threshold' is lowered, allowing for other related events, which would otherwise be seen as too trivial, to make it to the news.

This way, media itself inflates the hype bubble and substantiates the mythological nature of the social drama. It is here that the performativity of the neo-myth can be observed, as it is no longer the actual political issue at hand that is the important factor in perpetuating it, but the dramatism and public agitation itself. If men define situations as real, they are real in their consequence (Thomas and Thomas 1928: 572). This way, largely schematic and partially fictional, the neo-myth constitutes meta reality of the hyper-mediated public sphere.

It is widely argued that a certain kind of framing is more likely to occur as a result of news outlets trying to sensationalize certain issues and attract public attention. In such fashion, issues are being framed as 'problems' in the US media (Altheide 1997). Negative framing is also likely to encourage people think and discuss issues more (Hallahan 1999: 208). In times of social media, a media hype can be caused by a 'twitter storm' (Vasterman, 2018). Wien and Elmelund-Præstekær (2009) also discuss the process of hype-making, when the rise in issue salience is artificially media-generated. In other words, paradoxically, the more different voices participate in the social drama, the more performative attention the neo-myth gains.

Another interesting question, however, is: what determines the process of the diminishing issue-attention in relation to other issues? When and how do some issues overwhelm the others, and what factors affect this dynamic? Literature on 'issue fatigue' is not as abundant as it is on news hypes, but much of the latter actually incorporates some discussion on the former. Chen et al. (2003) introduce an Aging theory, which analyses news life cycles similarly to life cycles of live organisms, where an issue rises and wanes more or less rapidly, based on the 'nutrition' of the news that nurtures the discourse. As previously discussed, media hypes feed off inflated news content, which, if not supported by recurring trigger events, gradually diminish in their 'nutritional value', prompting reduction in public interest.

In addition, other news issues and social dramas compete over public attention as well. Nisbet et al. (2007: 196) notice that even during the peak moments of public interest with a particular issue, it might not at all be sensational in the context of other, competing ones. Its salience depends on other factors, such as the policy sphere that the issue derives from; news policy in the country and the framing efforts by the interested parties; the journalists' tendency to represent the issue based on publicly accepted values and norms; and the context of other issues, simultaneously competing over public attention.

According to Wien and Elmelund-Præstekær (2009: 197), issue life cycles in most cases tend to consist of approximately two to three cyclical waves and last an average of three weeks, but some might linger longer or otherwise be very rapid. This depends on a variety of reasons, the main being public boredom (Neuman 1990, Vasterman 2005, Henry and Gordon 2001, Hilgartner and Bosk 1988, Kingdon 1995) and competing issues that displace existing issues from the media agenda (Brosius 
and Kepplinger 1995, Geiß 2011). In Victor Turner's terms, the social drama either loses its dramatism, or is resolved.

Literature on news media suggests that what affects the dynamic of news issue life cycles is the agency of political actors, who are either interested in setting an agenda for the way a news story is told, or whose comments and actions actually structure the very narrative of the story. While Framing theory is usually employed in distinguishing how issues are being depicted to the public by the media, the role of political and public agents is usually associated with agenda setting, that is, which issues come to the fore in media coverage and what factors define this.

As previously discussed, however, political actors cannot be considered fully independent variables in the issue attention cycles, as their behavior is also influenced by the media dynamics. Mathes and Pfetsch, (1991) argue that some media outlets function as 'media leaders' that dictate the salience of issues to other outlets. Waldherr (2014) conducted a modeling experiment that demonstrates the overwhelming importance of journalists in creating news-waves. It suggests that what shapes issueattention cycles in the media, is adaptive reporting. "The self-reinforcing process of inter-media agenda setting between journalists with heterogeneous attention thresholds stands out as the key mechanism for generating this specific pattern of news waves" (p. 868).

However, the 'sponsors', or other actors that participate in the discursive process are responsible for the deviations and distortions of the standard cyclical news-wave model. In terms of political and public actors involved, they are usually divided into media, public and policy actors. However, in this context, Nisbet et al. (2007) note that public discussions and opinions of politicians dominate the discourse during the rising period of the wave, and expert, policy and technical discussions dominate the waning period. Kimrey (2016) discusses how next to public attention to issues, that of policy makers is no less important, as it is this increased interest in an issue that creates 'policy windows' for new legislation. Wolfsfeld and Sheafer (2006) argue that some issues are more likely to provide space for different stakeholders to participate than others. The more attention and news-space is given to an issue, the more chances for a variety of political actors to participate in the debate.

Therefore, the dramatic rise and fall of a public issue can be said to depend on a breach event, media framing of the myth, the focus and eventual oversaturation of the neo-myth. In addition, other issues become more important to the public, and the dramatic element recedes from the public attention, only to possibly return under different circumstances, for instance, when a new trigger event re-ignites the residual social or political tensions from the previous cycles.

\section{Neo-myths getting 'lost in translation'}

Communication is never fully rational or transparent. It is this space for interpretation and performative complexity that creates space for both dramatism and stereotypization of the rational knowledge exchange. However, if a social 
drama fails to adhere to a stereotypical script, it may deviate from a standard neomythological structure. There are different ways in which neo-myths are performed and experienced as social dramas.

One of the reasons that re-shape Downs's model of a full news wave is, according to Petersen (2009), 'asymmetry of comprehension' between the specialists who are dealing with the issue at hand, and the general public. Petersen adapted the issueattention cycle model to topics of international terrorism in the US. He argues that in theory, the society nowadays is supposed to be better informed than in the 70's, when Downs formulated his theory. This is supposed to result in more frequent and stronger public concerns with political issues. In fact, however, this is not at all the case. The author explains that this is due to the fact that the discursive framing that is used by the specialists when analyzing the issue is not always fully comprehended by the broader society.

This results in some old issues spiking back to prominence during the decline phase of the cycle, as if they were unheard news. Hence, "due to a failure to understand the complexity of international terrorism, the issue could become mired in a process whereby it cycles through stages two (alarmed discovery and euphoric enthusiasm) through four (decline in interest) rather than progress linearly into the final stage of a twilight realm where only the bureaucracy remains" (Petersen 2009: 11). Due to the complexity of both the information and the communication process itself, the 'lack of public education' argument might not be sufficient to explain the processes. Peterson's example alludes to is a certain 'knowledge loop' that forms as a result of public consumption of stereotypical media frames and the mythological nature of the mediatized mass communication altogether. Performative schematicism of neo-myths could perhaps also explain the rising popularity of conspiracy theories during the COVID-19 pandemic and science-skepticism. It could be that due to this knowledge loop, specialist narratives and frames fail to integrate into stereotypical scripts of mass-mediated neo-myths consecutively, creating new social dramas.

There is also culturally driven variation to Downs's model (Lörcher and Neverla 2015). Jung Oh et al. (2012) report that the news cycles on the same issues (H1N1 pandemic) differ in South Korean and US contexts. The reason for these differences is variation in political culture and news frames used by the media. Other comparative studies also unveil differences in how political issues are being constructed, framed and hence reciprocated within their life cycles. Beaudoin (2007) discusses how the prevalence (and hence the emotional charge) of news frames used for reporting on SARS epidemic differ between US and China. Luther and Zhou (2005) show how the same topic differs between China and the U.K. Meanwhile, Brossard et al. (2004) demonstrate how news coverage and framing of global warming differs between the US and French press. They conclude that the difference in the dynamic of issue life cycles depends on the local specificity both in terms of reporting and political culture.

The form of the neo-myths therefore varies depending on cultural and contextual factors. Waldherr (2012) suggests that the four main reasons for variation in issue attention cycles are stakeholders, their constellations (a more conflicting narrative 
implies quicker cycles), events that perpetuate the news cycle and the nature of issues themselves. There are also different types of how these social dramas are performed in the public. Geiß (2018) separates four main 'types of issues': bursting issues, struggling issues and flatline issues, routine issues and launching issues. Regardless of these variations, however, the cyclical logic as well as certain dramaticism in the neo-myths' content remains constant. Without the former, social dramas would never wane, and without the latter they would never emerge as 'issues' in the first place.

\section{Conclusion}

This article serves as an invitation for a discussion regarding the somewhat stereotypical and mythological nature of the contemporary mediatized public culture. It presented a theoretical outline for understanding the discursive and performative dynamics in the contemporary mediatized public sphere as consisting of a set of loosely scripted and stereotypically driven neo-myths. It argued that due to the specificities of the mass communication in a digital, mediatized world, news issues are rendered into cyclical, performative and stereotypical social dramas, perpetuated equally by the media, public and political actors. As such they function as modern participatory myths, that provide the plural and kaleidoscopic digital public discourse with form and meaning.

The structuring of neo-myth happens via news frames and social schemes that emerge as a result of mediatization processes. All neo-myths have stages of development, from their emergence to their waning, which coincide with the dramatic stages of news issue development. The more controversial the social drama, and more inclusive the range of actors and parties involved, the more impactful are these neomythological performances. Political agents become both the causes and the subjects to the dramatic process that is unfolding as a result. This constitutes the performative nature of the neo-myths; as discursive patterns begin acting as conditions for actors to perpetuate the mythological plot.

The rise of public interest and proliferation of dramatic intensity of the neo-myth is related to the nature of the contemporary media, which tends to create mediahypes that escalate and over-expose certain aspects of the social drama, this way generating its mythological form. Through creating a media hype, the discourse perpetuates itself, creating hyper-real conditions, which in turn provoke reaction and performative participation from public and political agents. The waning effect is reached when either a resolution at the political level is reached, the issue loses its emotional and sensational charge, the public becomes bored, or other, more salient issues overwhelm public attention.

While following a similar structural pattern, neo-myths vary based on specific media and cultural conditions. They may enter a 'knowledge loop', where certain elements of the plot provoke enhanced reaction from the public. Some issues may have a culturally specific plot, depending on the local media, policy and discursive context. This stands to demonstrate that neo-myths are fluid in structure and differ from the traditional mythological constructs. 
This article being what it is, a theoretical provocation, would of course require an empirically grounded confirmation or rejection. However, what it implies is a cardinal shift in the way the public sphere is being structured in the digital age in comparison to one of traditional media. Mediatization and news-oversaturation render narratives, social dramas and political performance schematic and mythological, and political and public reactions ritualistic. This in no way means that the process becomes meaningless. What it means, however, is that the digital age paradoxically itself makes a circular move towards a knowledge structure that is much more grounded in the mythological rather than the enlightened thought and practice.

\section{Acknowledgements}

This article is part of a project 'Policy Issue Life Cycles in Lithuanian Media (CYCLE)', Funded by the Research Council of Lithuania (grant no S-MIP-20-14).

Address:

Arvydas Grišinas

Faculty of Social Sciences, Arts and Humanities

Kaunas University of Technology

A. Mickevičiaus g. 37

Kaunas 44244

Lithuania

E-mail: arvydas.grisinas@ktu.lt

\section{References}

Alexander, Jeffrey (2017) The drama of social life. Cambridge: Polity.

Altheide, David L. (1997) "The news media, the problem frame, and the production of fear". The Sociological Quarterly 38, 4, 647-668. Available online at <www.jstor.org/stable/4121084>. Accessed on 2 November 2021.

Bacot, Hunter and Michael R. Fitzgerald (1999) "Issue salience, news coverage, and attention cycles of environmental problems”. Southeastern Political Review 27, 525-543. DOI: 10.1111/j.17471346.1999.tb00548.x

Barthes, Roland (1972) Mythologies. New York: Hill and Wang.

Beaudoin, Christopher E. (2007) "SARS news coverage and its determinants in China and the US". International Communication Gazette 69, 6, 509-524. DOI:10.1177/1748048507082839

Boydstun, Amber E., Justin H. Gross, Philip Resnik, and Noah A. Smith (2013) "Identifying media frames and frame dynamics within and across policy issues". In New directions in analyzing text as data workshop. London. Available online at $<\mathrm{http}$ //faculty.washington.edu/jwilker/559/ frames-2013.pdf $>$. Accessed on 13 January 2022. 
Brossard, Dominique, James Shanahan, and Katherine McComas (2004) "Are issue-cycles culturally constructed? A comparison of French and American coverage of global climate change". Mass Communication and Society 7, 3, 359-377. DOI: 10.1207/s15327825mcs0703_6

Brossard, Dominique, James Shanahan, and T. Clint Nesbitt (2007) The public, the media and agricultural biotechnology. Wallingford, UK: CABI.

Brosius, Hans-Bernd and Matthias H. Kepplinger (1995) "Killer and victim issues: issue competition in the agenda-setting process of German television". International Journal of Public Opinion Research 7, 211-231. DOI: 10.1093/ijpor/7.3.211

Campbell, James (1993) The hero with a thousand faces. London: Fontana Press.

Campbell, James (1972) Myths to live by. New York: Bantam Books.

Chen Chien C., Yao-Tsung Chen, Yeali Sun Meng, and Chang Chen (2003) "Life cycle modeling of news events using aging theory”. In Nada Lavrač, Dragan Gamberger, Hendrik Blockeel, and Ljupčo Todorovski, eds. Machine learning: ECML 2003, 47-59. Berlin, Heidelberg: Springer. DOI: 10.1007/978-3-540-39857-8_7

"COVID-19: tracking the impact on media consumption". Nielsen, 16 June 2020. Available online at $\quad<$ https://www.nielsen.com/us/en/insights/article/2020/covid-19-tracking-the-impact-onmedia-consumption/>. Accessed on 2 November 2021.

Crow, Deserai A. and Andrea Lawlor (2016) "Media in the policy process: using framing and narratives to understand policy influences". Review of Policy Research 33, 5, 472-491. Available online at $<$ https://onlinelibrary.wiley.com/doi/10.1111/ropr.12187>. Accessed on 2 November 2021.

de Vreese, Claes H. (2005) "News framing: theory and typology". Information Design Journal + Document Design 13, 1, 51-62.

Djerf-Pierre, Monika (2013) "Green metacycles of attention: reassessing the attention cycles of environmental news reporting 1961-2010”. Public Understanding of Science 22, 4, 495-512. DOI: https://doi.org/10.1177/0963662511426819

Downs, Anthony (1972) "Up and down with ecology the 'issue-attention cycle"'. The Public Interest $28,38-50$.

Eliade, Mircea (1971) The myth of the eternal return: cosmos and history. Princeton: Princeton University Press.

Geiß, Stefan (2011) "Patterns of relationships between issues: an analysis of German prestige newspapers”, International Journal of Public Opinion Research 23, 265-286. DOI: 10.1093/ijpor/ edq050

Geiß, Stefan (2018) "The dynamics of media attention to issues: towards standardizing measures, dimensions, and profiles". In Peter Vasterman, ed. From media hype to twitter storm. Amsterdam: Amsterdam University Press. DOI:10.2307/j.ctt21215m0.8

Gupta, Kuhika, Hank Jenkins-Smith (2016) “Anthony Downs, 'Up and down with ecology: the 'issueattention' cycle"'. In Steven J. Balla, Martin Lodge, and Edward C. Page, eds. The Oxford handbook of classics in public policy and administration. Oxford: Oxford University Press. DOI: 10.1093/oxfordhb/9780199646135.013.34

Hallahan, Kirk (1999) "Seven models of framing: implications for public relations". Journal of Public Relations Research 11, 3, 205-242. DOI: 10.1207/s1532754xjprr1103_02

Henry, Gary T. and Craig S. Gordon (2001) "Tracking issue attention: specifying the dynamics of the public agenda". The Public Opinion Quarterly 65, 2, 157-177. DOI: 10.1086/322198 
Hilgartner, Stephen and Charles L. Bosk (1988) "The rise and fall of social problems: a public arenas model". American Journal of Sociology 94, 1, 53-78. Available online at $<\mathrm{http}$ ://www.jstor.org/ stable/2781022>. Accessed on 2 November 2021.

Howlett, Michael (1997) "Issue-attention and punctuated equilibria models reconsidered: an empirical examination of the dynamics of agenda-setting in Canada". Canadian Journal of Political Science / Revue Canadienne de Science Politique 30, 1, 3-29. Available online at <https:// www.jstor.org/stable/3232165>. Accessed on 2 November 2021.

Jung, Carl G. (1928) Contributions to analytical psychology. H. G. Baynes and C. F. Baynes, eds. London: Routledge \& Kegan Paul.

Jung Oh, Hyun, Thomas Hove, Hye-Jin Paek, Byoungkwan Lee, Hyegyu Lee, and Sun Kyu Song (2012) "Attention cycles and the H1N1 pandemic: a cross-national study of US and Korean newspaper coverage". Asian Journal of Communication 22, 2, 214-232. DOI: $10.1080 / 01292986.2011 .642395$

Kalpokas, Ignas (2019) A political theory of post-truth. Cham: Palgrave Pivot.

Kimrey, Christopher M. (2016) "Opportunities in crisis and catastrophe: the issue-attention cycle and political reality”. Homeland Security Affairs 12, 1-14. Available online at <https://www.hsaj. org/articles/10541>. Accessed on 2 November 2021.

Kingdon, John W. (1995) Agendas, alternatives, and public policies. 2nd ed. New York: Harper Collins. Liu, Xinsheng, Arnold Vedlitz, and Letitia Alston (2008) "Regional news portrayals of global warming and climate change". Environmental Science \& Policy 11, 5, 379-393. DOI: 10.1016/ j.envsci.2008.01.002

Lörcher, Ines and Irene Neverla (2015) "The dynamics of issue attention in online communication on climate change". Media and Communication 3, 1, 17-33. DOI: http://dx.doi.org/10.17645/mac. v3i1.253

Luther, Catherine A. and Xiang Zhou (2005) "Within the boundaries of politics: news framing of SARS in China and the United States". Journalism and Mass Communication Quarterly 82, 857-872.

McCombs, Maxwell. E. (2004) Setting the agenda: the mass media and public opinion. Cambridge: Polity.

Mathes, Rainer and Barbara Pfetsch (1991) "The role of the alternative press in the agenda-building process: spill-over effects and media opinion leadership". European Journal of Communication 6, 1, 33-62. DOI:10.1177/0267323191006001003

Molotch, Harvey and Marilyn Lester (1974) "News as purposive behavior: on the strategic use of routine events, accidents, and scandals". American Sociological Review 39, 1, 101-112. Available online at <http://www.jstor.org/stable/2094279>. Accessed on 2 November 2021.

Neuman, Russel W. (1990) “The threshold of public attention”. Public Opinion Quarterly 54, 159-176.

Neuman, Russel W., Marion R. Just, and Ann N. Crigler (1992) Common knowledge: news and the construction of political meaning. Chicago: University of Chicago Press.

Nisbet, Matthew C., Dominique Brossard, and Adrianne Kroepsch (2003) "Framing science: the stem cell controversy in an age of press/politics". The International Journal of Press/Politics 8, 2, 36-70. DOI:10.1177/1081180x02251047

Nisbet, Matthew C., M. Huge, D. Brossard, J. Shanahan, and T. C. Nesbitt (2007) "Where do science debates come from? Understanding attention cycles and framing". In: Dominique Brossard, J. Shanahan, and T. C Nesbitt, eds. The public, the media and agricultural biotechnology. Wallingford, UK: CABI. DOI:10.1079/9781845932046.0193 
Petersen, Karen (2010) “Revisiting Downs's issue-attention cycle: international terrorism and U.S. Public Opinion". Journal of Strategic Security 2, 4, 1-16. DOI: 10.5038/1944-0472.2.4.1

Pettitt, Thomas (2012) "Bracketing the Gutenberg parenthesis". Explorations in Media Ecology 11, 2, 95-114. DOI: https://doi.org/10.1386/eme.11.2.95_1

Reese, Stephen D., Oscar H. Gandy, Jr., and August E. Grant, eds. (2001) Framing public life: perspectives on media and our understanding of the social world. Mahwah, NJ: Lawrence Erlbaum.

Shanahan, Elizabeth A., Mark K. McBeth, Paul L. Hathaway, and Ruth J. Arnell (2008) "Conduit or contributor? The role of media in policy change theory". Policy Sciences 41, 2, 115-138. DOI: 10.1007/s11077-008-9058-y

Schaffner, Brian F. and Patrick J. Sellers (2009) Winning with words: the origins and impact of political framing. London: Routledge.

Semetko, Holli A. and Patti M. Valkenburg (2000) "Framing European politics: a content analysis of press and television news". Journal of Communication 50, 93-109. DOI: https://doi. org/10.1111/j.1460-2466.2000.tb02843.x

Stanyer, James (2014) "Hypes, waves, and storms: events and the dynamics of their coverage". In: Carsten Reinemann, ed. Political communication. Berlin: De Gruyter Mouton.

Stier, Sebastian et al. (2018) "Election Campaigning on Social Media: Politicians, Audiences, and the Mediation of Political Communication on Facebook and Twitter." Political Communication 35:1: 50-74.

Strömbäck, Jesper and Frank Esser (2014) "Mediatization of politics: towards a theoretical framework". In Frank Esser and Jesper Strömbäck, eds. Mediatization of politics. London: Palgrave Macmillan. DOI: 10.1057/9781137275844_1

Teixeira, Thales (2015) "When people pay attention to video ads and why". Harvard Business Review, 14 October. Available online at $<$ https://hbr.org/2015/10/when-people-pay-attention-to-videoads-and-why>. Accessed on 2 November 2021.

Thomas, William I. and Dorothy S. Thomas (1928) The child in America. New York: Knopf.

Thunström, Linda, and Shiri Noy (2019) "The value of thoughts and prayers". Proceedings of the National Academy of Sciences 116, 40, 19797-19798. DOI: 10.1073/pnas.1908268116

Turner, Victor (1974) “Liminal to liminoid, in play, flow, and ritual: an essay in comparative symbology". Rice Institute Pamphlet - Rice University Studies 60, 3, 53-92. Available online at $<\mathrm{https}: / / \mathrm{hdl}$. handle.net/1911/63159>. Accessed on 2 November 2021.

Turner, Victor (1980) "Social dramas and stories about them". Critical Inquiry 7, 1, 141-168. Available online at $<$ https://www.jstor.org/stable/1343180>. Accessed on 2 November 2021.

Vasterman, Peter L. M. (2005) "Self-reinforcing news waves, journalistic standards and the construction of social problems". European Journal of Communication 20, 4, 508-530.

Vasterman, Peter, ed. (2018) From media hype to twitter storm. Amsterdam: Amsterdam University Press. DOI: $10.2307 /$ j.ctt $21215 \mathrm{~m} 0$

Waldherr, Annie (2012) Die Dynamik der Medienaufmerksamkeit. Baden-Baden: Nomos Verlagsgesellschaft.

Waldherr, Annie (2014) "Emergence of news waves: a social simulation approach". Journal of Communication 64, 5, 852-873. DOI:10.1111/jcom.12117

Wien, Charlotte and Christian Elmelund-Præstekær (2009) “An anatomy of media hypes”. European Journal of Communication 24, 2, 183-201. DOI:10.1177/0267323108101831 
Wolfsfeld, Gadi and Tamir Sheafer (2006) "Competing actors and the construction of political news: the contest over waves in Israel". Political Communication 23, 3, 333-354. DOI: $10.1080 / 10584600600808927$ 